\title{
A Mechanistic Study of Precursor Evolution in Colloidal II-VI Semiconductor Nanocrystal Synthesis
}

Supporting Information

Haitao Liu, Jonathan S. Owen, and A. Paul Alivisatos*

Department of Chemistry, University of California, Berkeley, and Materials Science Division, Lawrence Berkeley National Laboratory, Berkeley, CA 94720, USA.

Table of Contents

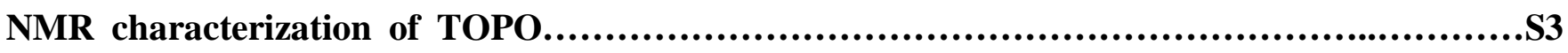

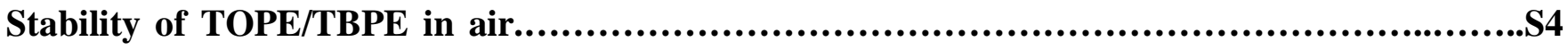

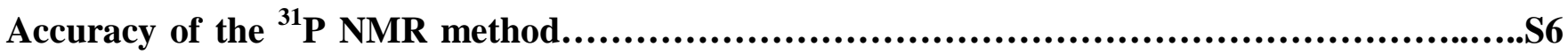

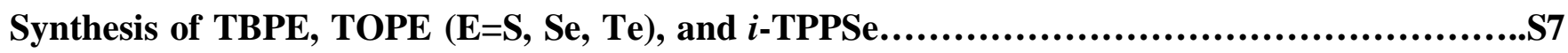

Detailed experimental procedure of Karl-Fischer titrations........................................S9

Product characterization of the synthesis of ME $(\mathrm{M}=\mathrm{Zn}, \mathrm{Cd}$; E=S, Se, Te) …..................S12

Detailed experimental procedure of the $\mathrm{H}_{2}{ }^{18} \mathrm{O}$-TOP ${ }^{16} \mathrm{O}$ isotope exchange.....................S17

Measurement of activation parameters...........................................................S18

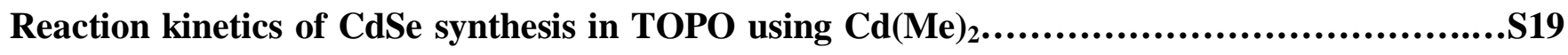

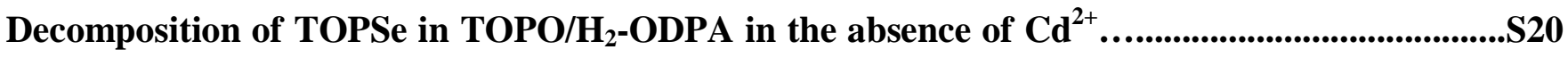

Reference.......................................................................................... 


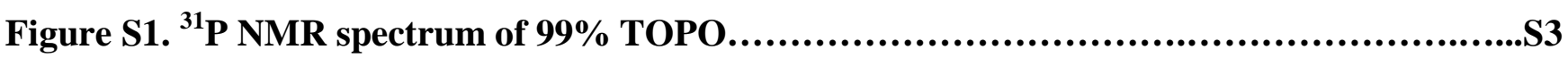

Figure S2. ${ }^{31} \mathrm{P}$ NMR spectrum of TOPSe after it was stored in air for 20 day....................S4

Figure S3. Deconvolution of the TOPO and TOPS resonances using MestRec.......................S5

Figure S4. FAB-MS spectrum of the reaction between Cd-OA and TBPSe........................S10

Figure S5. FAB-MS spectrum of the CdSe synthesis in TOPO using Cd-ODPA and TBPSe.....S11

Figure S6. Full ${ }^{13} \mathrm{C}$ NMR spectrum of the reaction between Cd-OA and TBPSe.................S12

Figure S7. ${ }^{13} \mathrm{C}$ NMR spectrum of the reaction between M-OA $(\mathrm{M}=\mathrm{Cd}, \mathrm{Zn})$ and TBPTe..........S14

Figure S8. Transmission electron micrograph of CdSe and CdS nanocrystals....................S15

Figure S9. UV-Vis spectrum of CdSe nanocrystals.............................................6

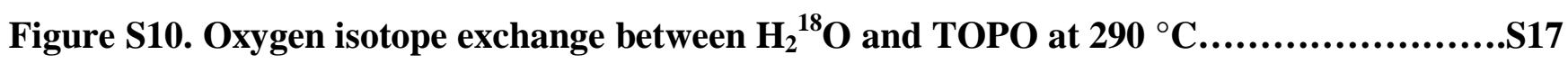

Figure S11. Reaction kinetics of CdSe synthesis using $\mathrm{Cd}(\mathrm{Me})_{2}$ as $\mathrm{Cd}$ precursor at $260{ }^{\circ} \mathrm{C} \ldots . . . . \mathrm{S} 19$

Figure S12. Reaction kinetics of $\mathrm{CdS}$ synthesis using $\mathrm{CdO}$ as $\mathrm{Cd}$ precursor at $290{ }^{\circ} \mathrm{C} \ldots \ldots . . . . . . \mathrm{S21}$ 
TOPO Purity. The purity of TOPO was analyzed with ${ }^{31} \mathrm{P}$ NMR spectroscopy. At least three impurities were found in 99\% TOPO purchased from Aldrich (Figure S2) which are very similar to those in $90 \%$ TOPO from Aldrich.

Figure S1. ${ }^{31} \mathrm{P}$ NMR spectrum of $99 \%$ TOPO (Aldrich, lot \# 24801MB) used in this study. The spectrum is enlarged to show the impurity peaks $(*)$. One of the impurity peaks $(\Delta=48.5 \mathrm{ppm})$ overlaps with a ${ }^{13} \mathrm{C}$ satellite of TOPO. The purity of TOPO in this sample was estimated to be $93 \%$ (mol/mol).

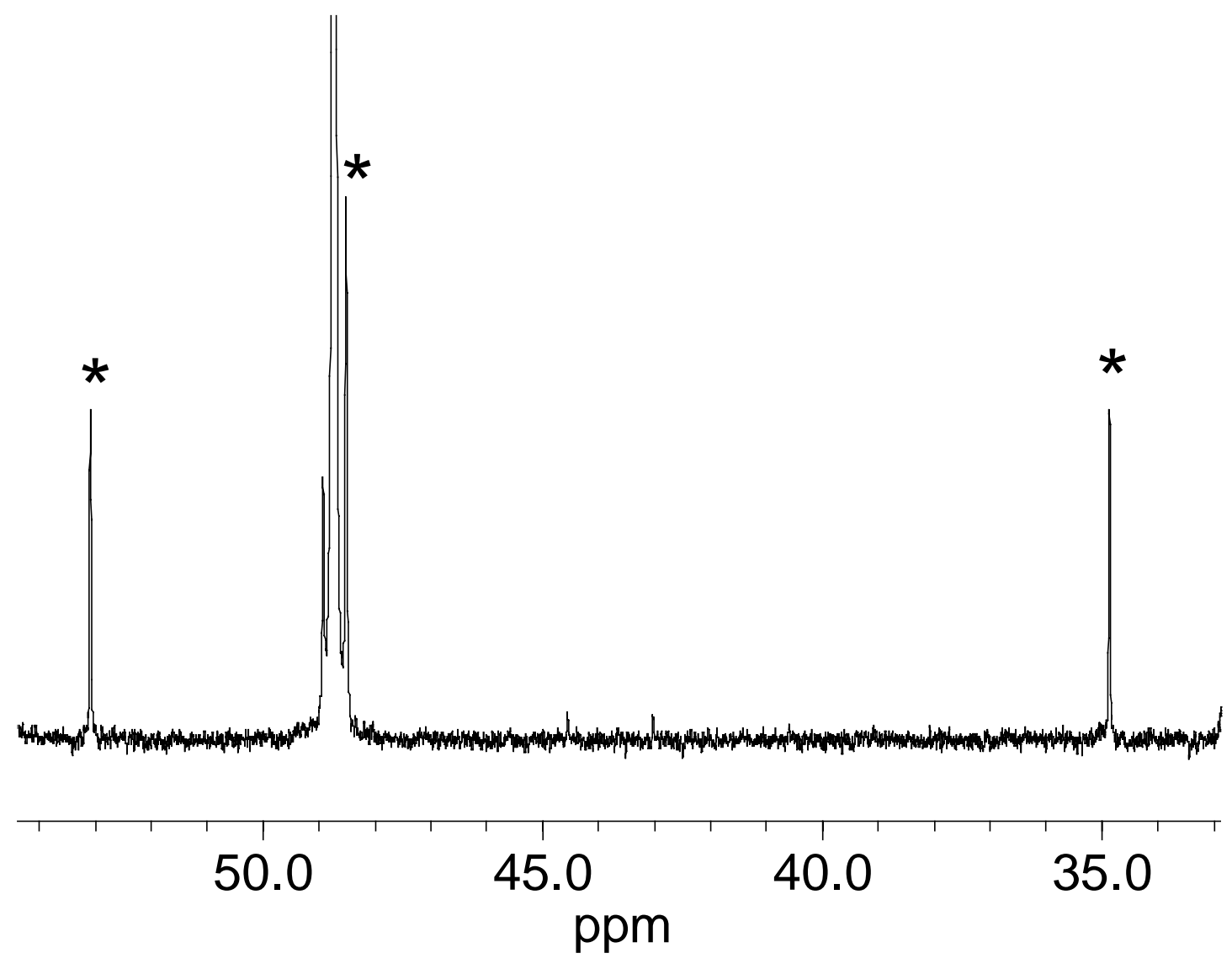


Stability of TOPSe/TBPSe/TBPS in air. TOPSe, TBPSe, and TBPS were found to be stable to air. No change was observed in the ${ }^{31} \mathrm{P}$ NMR spectrum for a $\mathrm{CDCl}_{3}$ solution of TOPSe that was left in air for 20 days (Figure $\mathrm{S} 1$ ). When Cd-ODPA was added to a $\mathrm{CDCl}_{3}$ solution of TOPSe, $<2 \%$ of TOPSe was converted to TOPO after 20 days. Similar results were obtained for $\mathrm{CDCl}_{3}$ solutions of TBPSe and TBPS after they were exposed to air for 5 days (data not shown).

Figure S2. ${ }^{31} \mathrm{P}$ NMR spectrum of a $\mathrm{CDCl}_{3}$ solution of TOPSe after it was stored in air for 20 days.

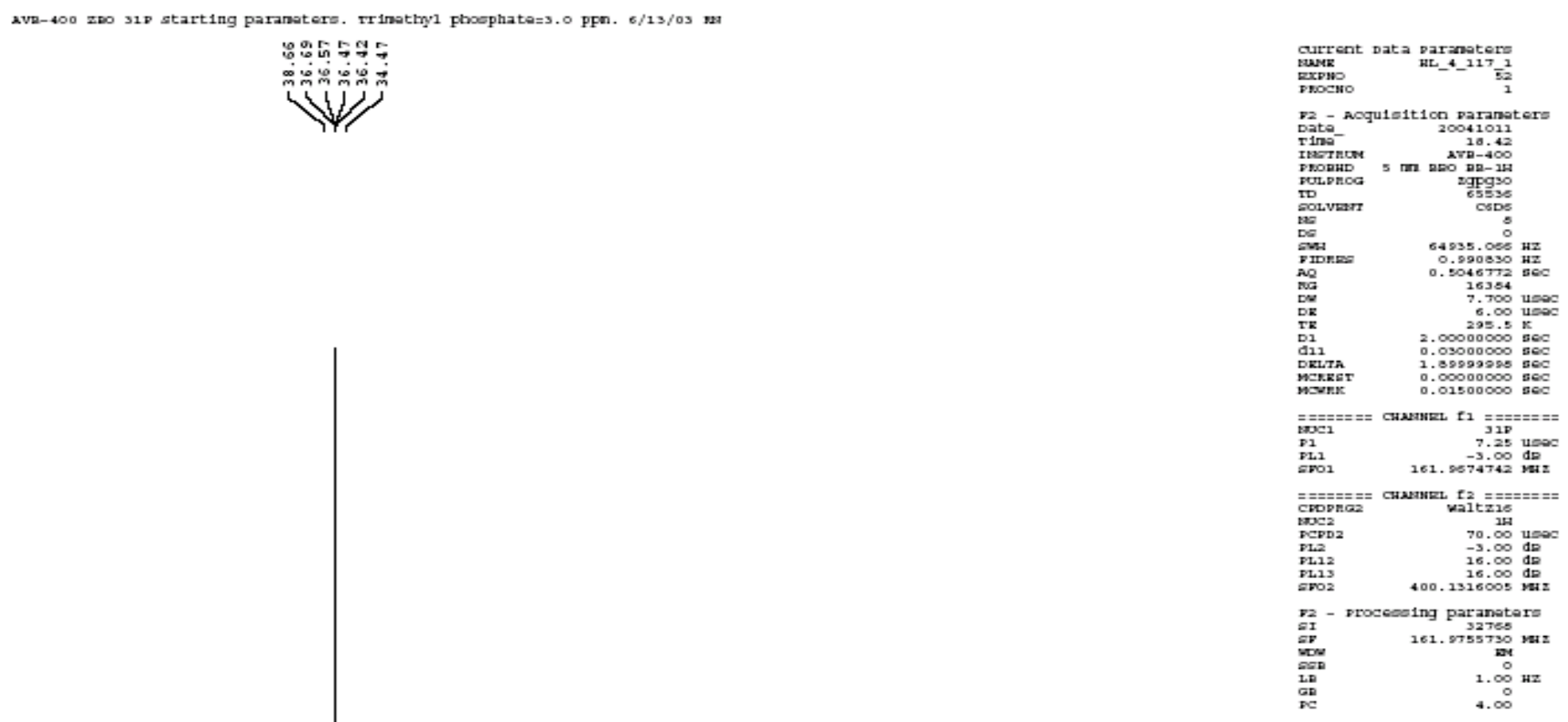


Figure S3. Deconvolution of the TOPO and TOPS resonances using MestRec. ${ }^{a}$

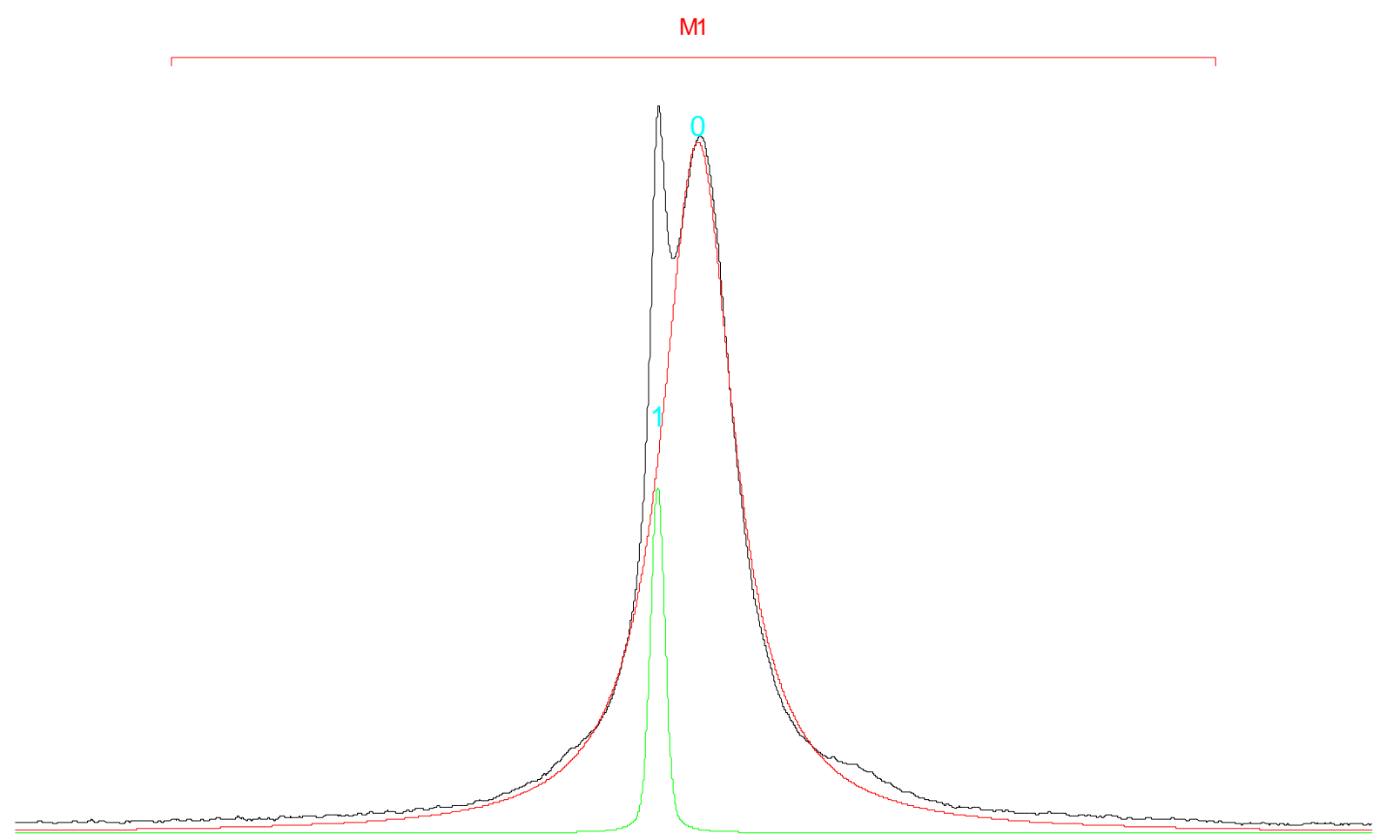

$\begin{array}{ccc}49.50 & 48.50 & 48.00\end{array}$

${ }^{a}$ Typical ${ }^{31} \mathrm{P}$ NMR spectrum of the crude reaction mixture of the synthesis of CdS in TOPO using 'double degassed' protocol. The red (TOPO) and green (TOPS) peaks are fitting result obtained using MestRec. 
Accuracy of the ${ }^{31} \mathbf{P}$ NMR method used in the kinetics studies. Reactions in TOPO: Solutions of TOPO/TOPSe mixture were prepared with known molar ratio $\left(\mathrm{R}_{\mathrm{M}}\right)$ based on the mass and assuming $100 \%$ purity. The corresponding ${ }^{31} \mathrm{P}$ spectra were collected and the molar ratio $\left(\mathrm{R}_{\mathrm{N}}\right)$ was calculated from the integration. A highly linear correlation $\left(R^{2}>0.999\right)$ was observed between $R_{M}$ and $R_{N}$. The $R_{N} / R_{M}$ value depends on the pulse program used, being 0.92 without proton decoupling and 1.07 with inverse gated proton decoupling (acquisition time $=10 \mathrm{sec}$.). If the signals of TOPSe and TOPS are assumed to have $20 \%$ error, fits of the [TOPE] decay versus time showed $<5 \%$ change in the fitted decay constant, which is within the error of the fitting. In-situ reactions: The ${ }^{31} \mathrm{P}$ NMR spectra of these reactions were collected using inverse gated proton decoupling with shorter acquisition time (3-4 sec.) compared to the above case. The concentration of TBPSe/TBPO obtained by NMR in this case was found to be accurate within $\pm 2 \%$ by comparing to an internal standard (ethyl phosphonic acid diethyl ester). 
Synthesis of TBPS: A mixture of TBP (2.02 g, $0.010 \mathrm{~mol})$ and sulfur $(0.435 \mathrm{~g}, 0.014 \mathrm{~mol})$ was stirred at r.t. in glove box overnight. The supernatant was used in the experiments without further purification. ${ }^{1} \mathrm{H}$ $\left(\mathrm{CDCl}_{3}, \Delta \mathrm{ppm}\right): 1.63-1.70(\mathrm{~m}, 6 \mathrm{H}), 1.37-1.47(\mathrm{~m}, 6 \mathrm{H}), 1.23-1.32(\mathrm{~m}, 6 \mathrm{H}), 0.79(\mathrm{t}, 9 \mathrm{H}, J=7.3 \mathrm{~Hz}) .{ }^{13} \mathrm{C}$ $\left(\mathrm{CDCl}_{3}, \Delta\right.$ ppm, more than 4 peaks appeared due to the coupling between ${ }^{13} \mathrm{C}$ and $\left.{ }^{31} \mathrm{P}\right): 30.49,29.99$, 24.11, 24.07, 23.69, 23.54, 13.31. ${ }^{31} \mathrm{P}\left(\mathrm{CDCl}_{3}, \Delta \mathrm{ppm}\right)$ : 48.7. Anal. (calcd, found): $\mathrm{C}(61.49,61.11), \mathrm{H}$ $(11.61,11.84)$. TBPSe, TBPTe, TOPSe, and TOPS were prepared similarly with longer reaction times. TBPSe: ${ }^{1} \mathrm{H}\left(\mathrm{CDCl}_{3}, \Delta \mathrm{ppm}\right): 1.73-1.79(\mathrm{~m}, 6 \mathrm{H}), 1.36-1.46(\mathrm{~m}, 6 \mathrm{H}), 1.23-1.33(\mathrm{~m}, 6 \mathrm{H}), 0.79(\mathrm{t}, 9 \mathrm{H}$, $J=7.3 \mathrm{~Hz}) .{ }^{31} \mathrm{P}\left(\mathrm{CDCl}_{3}, \Delta \mathrm{ppm}\right): 36.8, J_{\mathrm{P}-\mathrm{Se}}=680 \mathrm{~Hz}$. Anal. (calcd, found): C (51.24, 51.37), H $(9.68$, 9.78).

TBPTe: The mixture solidified into a yellow crystalline solid after it was stored in glove box at r.t. for 30 days. ${ }^{1} \mathrm{H}\left(\mathrm{CDCl}_{3}, \Delta \mathrm{ppm}\right): 1.96-2.03(\mathrm{~m}, 6 \mathrm{H}), 1.38-1.56(\mathrm{~m}, 12 \mathrm{H}), 0.93(\mathrm{t}, 9 \mathrm{H}, J=7.2 \mathrm{~Hz}) .{ }^{13} \mathrm{C}\left(\mathrm{CDCl}_{3}\right.$, $\Delta$ ppm): $\left.30.45,30.09,26.56,26.52,23.55,23.40,13.61 .{ }^{31} \mathrm{P}\left(\mathrm{CDCl}_{3}, \Delta \mathrm{ppm}\right):-13.2 . J_{\mathrm{P}-\mathrm{Te}}{ }^{125} \mathrm{Te}\right)=1655$ $\mathrm{Hz}, J_{\mathrm{P}-\mathrm{Te}}\left({ }^{123} \mathrm{Te}\right)=1370 \mathrm{~Hz}$.

TOPSe: ${ }^{1} \mathrm{H}\left(\mathrm{CDCl}_{3}, \Delta \mathrm{ppm}\right): 1.83-1.90(\mathrm{~m}, 6 \mathrm{H}), 1.49-1.59(\mathrm{~m}, 6 \mathrm{H}), 1.32-1.39(\mathrm{~m}, 6 \mathrm{H}), 1.22-1.29(\mathrm{~m}$ 24H), 0.84 (t, 9H, J=6.8 Hz). ${ }^{31} \mathrm{P}\left(\mathrm{CDCl}_{3}, \Delta \mathrm{ppm}\right): 36.4 . J_{\mathrm{P}-\mathrm{Se}}=678 \mathrm{~Hz} .{ }^{77} \mathrm{Se}\left(\mathrm{CDCl}_{3}, \Delta \mathrm{ppm}\right):-377,-386$. Anal. (calcd, found): C (64.11, 64.46), H(11.3, 11.65).

TOPS: ${ }^{1} \mathrm{H}\left(\mathrm{CDCl}_{3}, \Delta \mathrm{ppm}\right) .1 .72-1.79(\mathrm{~m}, 6 \mathrm{H}), 1.49-1.59(\mathrm{~m}, 6 \mathrm{H}), 1.32-1.37(\mathrm{~m}, 6 \mathrm{H}), 1.21-1.32(\mathrm{~m}$, 24H), 0.85 (t, 9H, J=6.6 Hz). ${ }^{31} \mathrm{P}\left(\mathrm{CDCl}_{3}, \Delta \mathrm{ppm}\right)$ : 48.6. Anal. (calcd, found): $\mathrm{C}(71.58,72.05), \mathrm{H}(12.77$, 13.06).

$i$-TPPSe: To a vial in a glove box was added tri-iso-propylphosphine $(0.80 \mathrm{~g}, 5.0 \mathrm{mmol})$ and Se powder $(0.40 \mathrm{~g}, 5.0 \mathrm{mmol})$. The mixture was stirred for 24 hours to give a white precipitate. Toluene $(1 \mathrm{~mL})$ was 
added to dissolve the precipitated material. The mixture was stirred for another two days before it was taken out of glovebox. Toluene $(1 \mathrm{~mL})$ was added to the mixture and unreacted Se was removed by filtration. The toluene solution was evaporated under $\mathrm{N}_{2}$ flow to crystallize the product. The solid product was collected by filtration and washed with cold toluene. Yield: $0.62 \mathrm{~g}, 52 \% .{ }^{1} \mathrm{H}\left(\mathrm{CDCl}_{3}, \Delta\right.$ ppm): $2.22-2.34(\mathrm{~m}, 3 \mathrm{H}), 1.25-1.31\left(\mathrm{dd}, 18 \mathrm{H}, J_{1}=7.2 \mathrm{~Hz}, J_{2}=16.2 \mathrm{~Hz}\right) .{ }^{13} \mathrm{C}\left(\mathrm{CDCl}_{3}, \Delta \mathrm{ppm}\right): 26.99$, 26.60, 18.11, 18.09. ${ }^{31} \mathrm{P}\left(\mathrm{CDCl}_{3}, \Delta \mathrm{ppm}\right): 69.6, J_{\mathrm{P}-\mathrm{Se}}=688 \mathrm{~Hz}$. 
Karl-Fischer titration. The moisture content of reactions and reagents in this study was determined by volumetric Karl-Fischer titration using HYDRANAL reagents (Aldrich). Briefly, $1.0 \mathrm{~g}$ of the sample to be titrated was mixed with $5.0 \mathrm{~g}$ of HYDRANAL-Solvent $2 \mathrm{E}$ and titrated by dropwise addition of HYDRANAL-Titrant 2E via a syringe in a glove box. The titration was stopped when the solution turns into yellow-brown color, which indicates the presence of unreacted titrant. A control experiment was done to determine the moisture content in the HYDRANAL-Solvent 2E which was deducted as a background from all the titration results.

Titration of the water produced during the dissolution of $\mathrm{CdO}$ in $\mathbf{H}_{2}$-ODPA/TOPO. To a $30 \mathrm{~mL}$ vial in a glove box was added TOPO (1.0 g), $\mathrm{H}_{2}$-ODPA (1.07 g, $\left.3.2 \mathrm{mmol}\right)$, and $\mathrm{CdO}(0.212 \mathrm{~g}, 1.6$ mmol). The vial was tightly capped and brought out of the glove box before it was heated to dissolve CdO. The vial was then brought into the glove box and the mixture was titrated using the method described above.

Determine the amount of water in the 'double degassed' reaction mixture. A mixture of TOPO/Cd-ODPA was prepared following the 'double degassed' protocol described in the main text using TOPO (2.73 g), $\mathrm{H}_{2}$-ODPA (1.07 g), and $\mathrm{CdO}(0.205 \mathrm{~g})$. The second degassing was carried out at $150{ }^{\circ} \mathrm{C}, 300 \mathrm{mtorr}$ for $5 \mathrm{~min}$. HYDRANAL-Solvent $2 \mathrm{E}(10 \mathrm{~mL})$ was added to the flask via a syringe at $100{ }^{\circ} \mathrm{C}$. The mixture was cooled to $30{ }^{\circ} \mathrm{C}$ and titrated as described above. The reaction mixture was vigorously shaken to ensure that water adsorbed on the reaction vessel and lower part of the condenser was also titrated. 
Figure S4. FAB-MS spectrum of the reaction between Cd-OA and TBPSe. ${ }^{\mathrm{a}}$

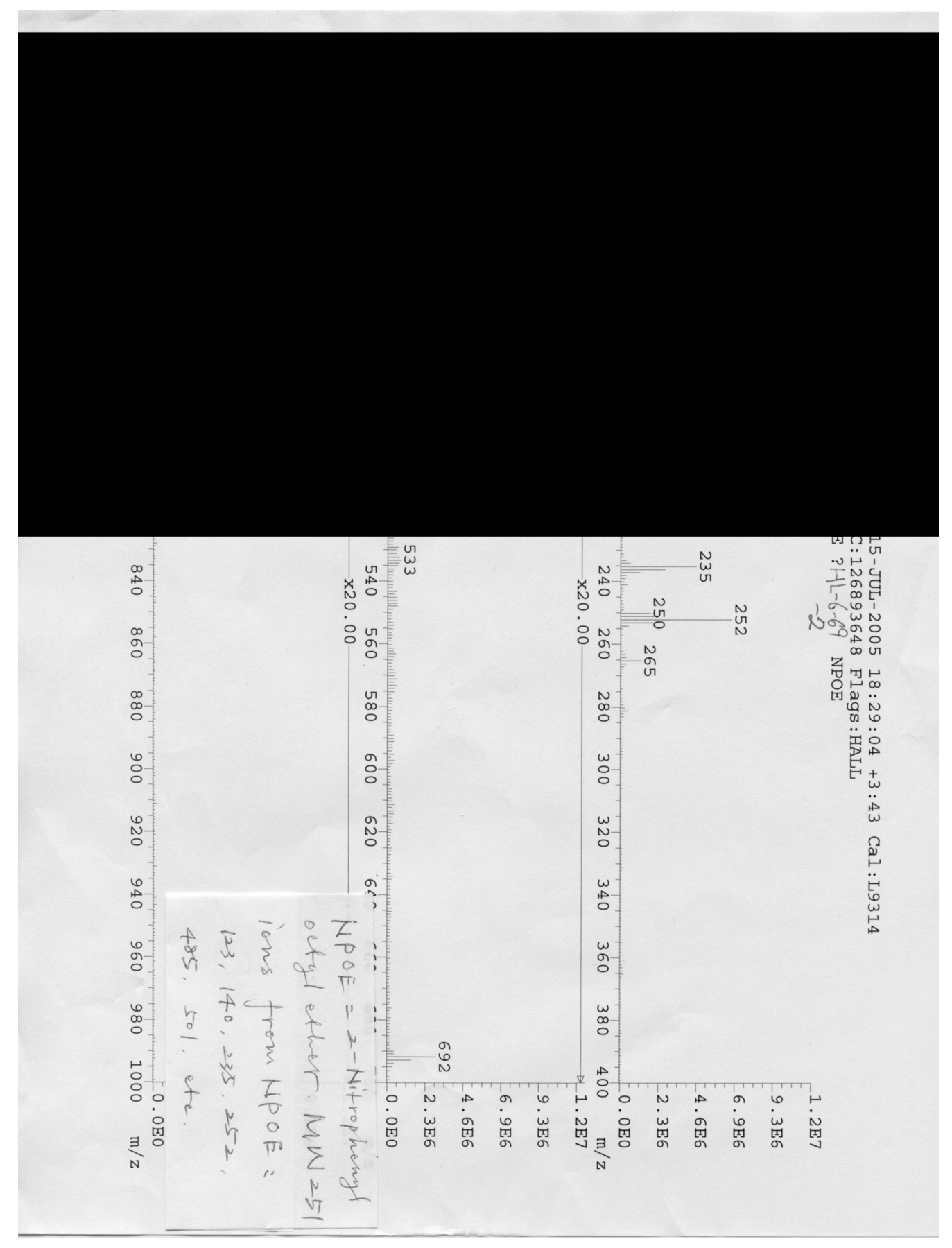

${ }^{\mathrm{a}}[\mathrm{TBPO}+\mathrm{H}]^{+}(m / z=219)$, 
Figure S5. FAB-MS of the reaction between Cd-ODPA and TBPSe in TOPO. ${ }^{a}$

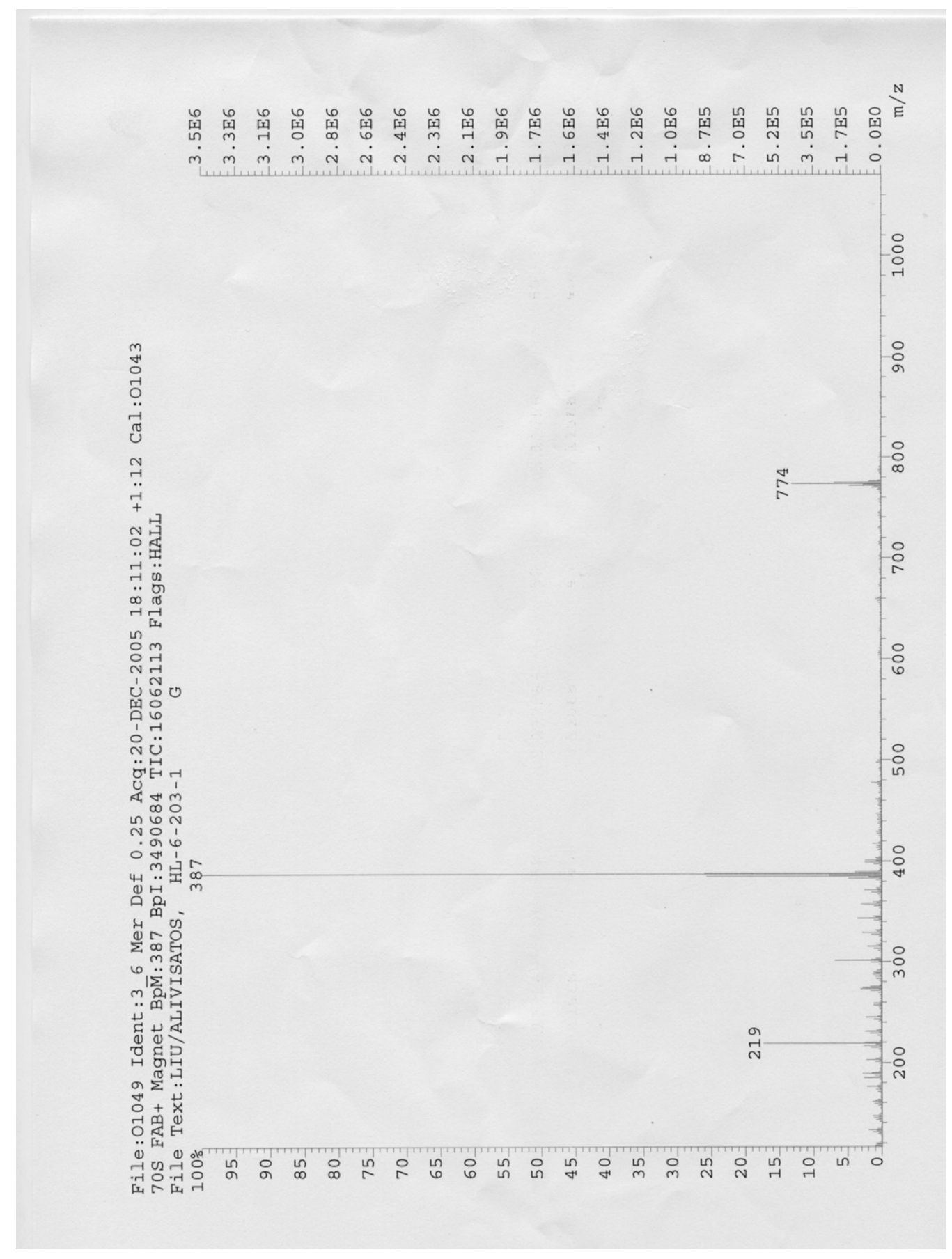

${ }^{\mathrm{a}}[\mathrm{TBPO}+\mathrm{H}]^{+}(\mathrm{m} / z=219),[\mathrm{TOPO}+\mathrm{H}]^{+}(\mathrm{m} / z=387)$, and $[2 \mathrm{TOPO}+\mathrm{H}]^{+}(\mathrm{m} / z=774)$ 
Figure S6. Full ${ }^{13} \mathrm{C}$ NMR spectrum of the reaction between Cd-OA and TBPSe in $n$-nonane- $d_{20}$.

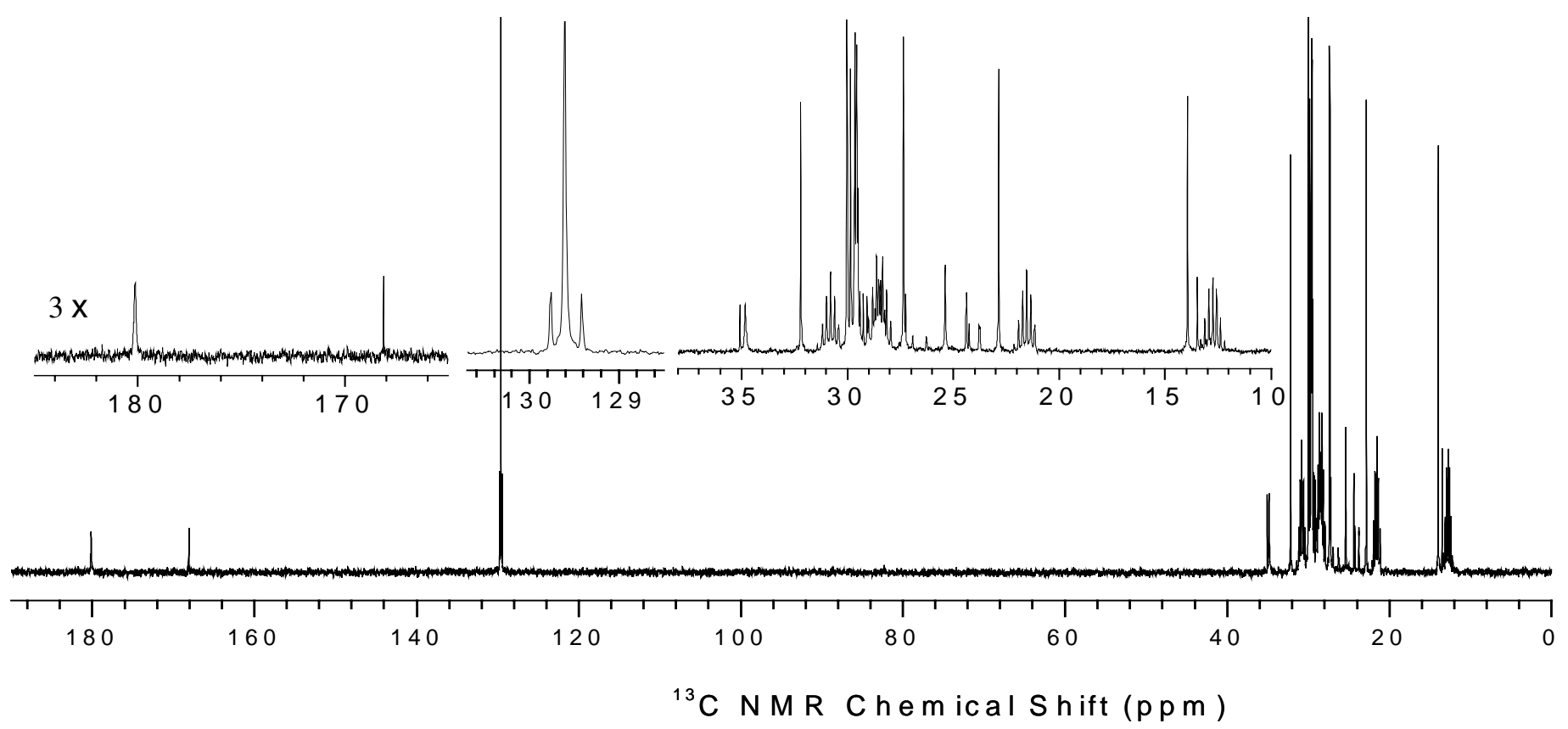

Synthesis of ME (M=Cd, Zn; E=S, Se, Te) in non-coordinating solvent in sealed NMR tube.

CdS: In a 5 mm NMR tube was added Cd-OA stock solution (0.14 g, $0.060 \mathrm{mmol} \mathrm{Cd})$, TBPS (16 mg, $0.068 \mathrm{mmol})$, and $n$-decane- $\mathrm{d}_{22}(0.30 \mathrm{~g})$. The mixture was degassed by three cycles of freeze-pump-thaw before it was flame sealed under reduced pressure (300 mtorr). The mixture was heated to $150{ }^{\circ} \mathrm{C}$ for 2.5 h. ${ }^{31} \mathrm{P}$ NMR $\left(\mathrm{C}_{9} \mathrm{D}_{20} / \mathrm{C}_{10} \mathrm{D}_{22}, \Delta \mathrm{ppm}\right)$ : 57.0 (TBPO, identified by addition of TBPO), 50.7 (TBPS). Selected $(\mathrm{OA})_{2} \mathrm{O}$ peaks in the ${ }^{13} \mathrm{C}$ NMR spectrum $\left(\mathrm{C}_{9} \mathrm{D}_{20} / \mathrm{C}_{10} \mathrm{D}_{22}, \Delta \mathrm{ppm}\right): 168.5,130.1,129.7$, and 35.4. CdTe: This is similar to the synthesis of CdSe in non-coordinating solvent using TBPTe. The mixture was heated to $120{ }^{\circ} \mathrm{C}$ in an oil bath for $20 \mathrm{~min} .{ }^{31} \mathrm{P} \mathrm{NMR}\left(\mathrm{C}_{9} \mathrm{D}_{20} / \mathrm{C}_{10} \mathrm{D}_{22}, \Delta \mathrm{ppm}\right): 52.9 \mathrm{ppm}$ (TBPO). 
Selected $(\mathrm{OA})_{2} \mathrm{O}$ peaks in the ${ }^{13} \mathrm{C}$ NMR spectrum $\left(\mathrm{C}_{9} \mathrm{D}_{20} / \mathrm{C}_{10} \mathrm{D}_{22}, \Delta \mathrm{ppm}\right): 168.7,130.1,129.8,35.4$. Figure S7 top.

ZnS: This is similar to the synthesis of CdSe in non-coordinating solvent using TBPS (62 mg, 0.26 mmol) and $\mathrm{Zn}-\mathrm{OA}$ stock solution $(0.64 \mathrm{~g}, 0.25 \mathrm{mmol} \mathrm{Zn})$ in ODE solvent. The mixture was heated to $265{ }^{\circ} \mathrm{C}$ in an oil bath for 42 min. ${ }^{31} \mathrm{P}$ NMR (crude reaction mixture, without ${ }^{2} \mathrm{H}$ lock, $\Delta \mathrm{ppm}$ ): 56.6 (TBPO), 46.3 (TBPS). Selected $(\mathrm{OA})_{2} \mathrm{O}$ peaks in the ${ }^{13} \mathrm{C}$ NMR spectrum (crude reaction mixture, without ${ }^{2} \mathrm{H}$ lock, $\left.\Delta \mathrm{ppm}\right):$ 167.9, 129.3, 129.0, 34.6.

ZnSe: This is similar to the synthesis of CdSe in non-coordinating solvent using TBPSe (77 mg, 0.27 mmol) and $\mathrm{Zn}-\mathrm{OA}$ stock solution $(0.64 \mathrm{~g}, 0.25 \mathrm{mmol} \mathrm{Zn})$ in ODE solvent. The mixture was heated to $265^{\circ} \mathrm{C}$ in an oil bath for $42 \mathrm{~min} .{ }^{31} \mathrm{P}$ NMR (without ${ }^{2} \mathrm{H}$ lock, $\Delta \mathrm{ppm}$ ): $53.6 \mathrm{ppm}$ (TBPO), 35.0 (TBPSe). Selected $(\mathrm{OA})_{2} \mathrm{O}$ peaks in the ${ }^{13} \mathrm{C}$ NMR spectrum (without ${ }^{2} \mathrm{H}$ lock, $\Delta$ ppm): 167.9, 129.3, 129.0, 34.6. ZnTe: This is similar to the synthesis of CdSe in non-coordinating solvent using TBPTe $(0.12 \mathrm{~g}, 0.36$ mmol), TBP (0.12 g, $0.59 \mathrm{mmol}), \mathrm{Zn}-\mathrm{OA}$ stock solution $(0.82 \mathrm{~g}, 0.32 \mathrm{mmol} \mathrm{Zn})$, and $n$-decane-d $\mathrm{d}_{22}(0.39$ g). The mixture was heated to $230{ }^{\circ} \mathrm{C}$ in an oil bath for $150 \mathrm{~min} .{ }^{31} \mathrm{P}$ NMR $(\Delta \mathrm{ppm}): 53.5 \mathrm{ppm}$ (TBPO), -25.0 (TBPTe and TBP, due to fast exchange of Te between TBPTe and TBP). ${ }^{13} \mathrm{C}$ NMR: Figure S7 bottom. 
Figure S7. ${ }^{13} \mathrm{C}$ NMR spectrum of the reaction between (Top) Cd-OA and TBPTe (Bottom) Zn-OA and TBPTe. ${ }^{\mathrm{a}}$
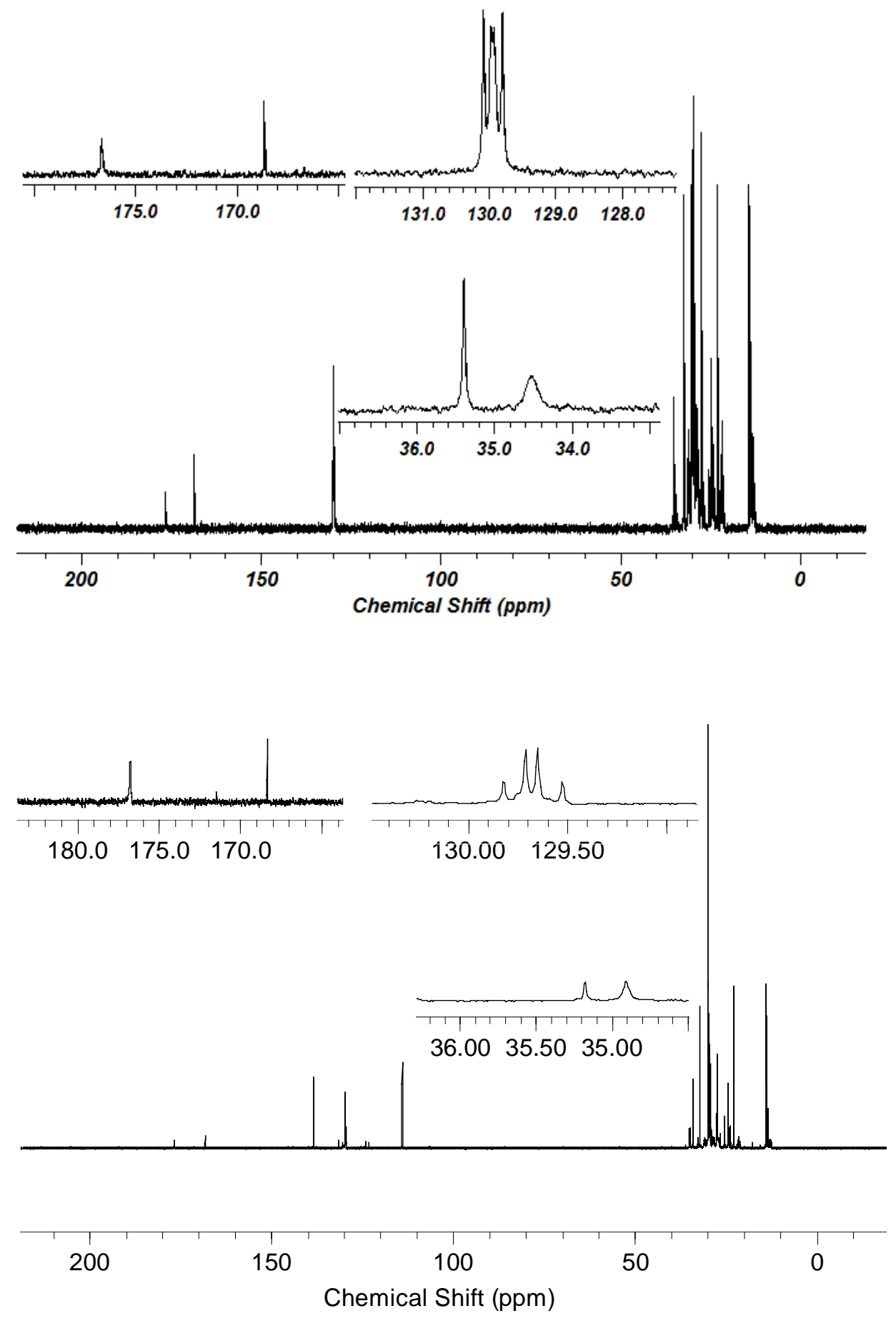

${ }^{a}$ The inserts show the peaks used to identify $(\mathrm{OA})_{2} \mathrm{O}$. 
Figure S8 Transmission electron micrograph of (A) CdSe nanocrystals prepared using Cd-ODPA and TOPSe in TOPO at $260{ }^{\circ} \mathrm{C}$ (B) CdS nanocrystals prepared using Cd-OPDA and TOPS in TOPO at 290 ${ }^{\circ} \mathrm{C}$. Scale bars represent $20 \mathrm{~nm}$ and $100 \mathrm{~nm}$ for CdSe and CdS, respectively.
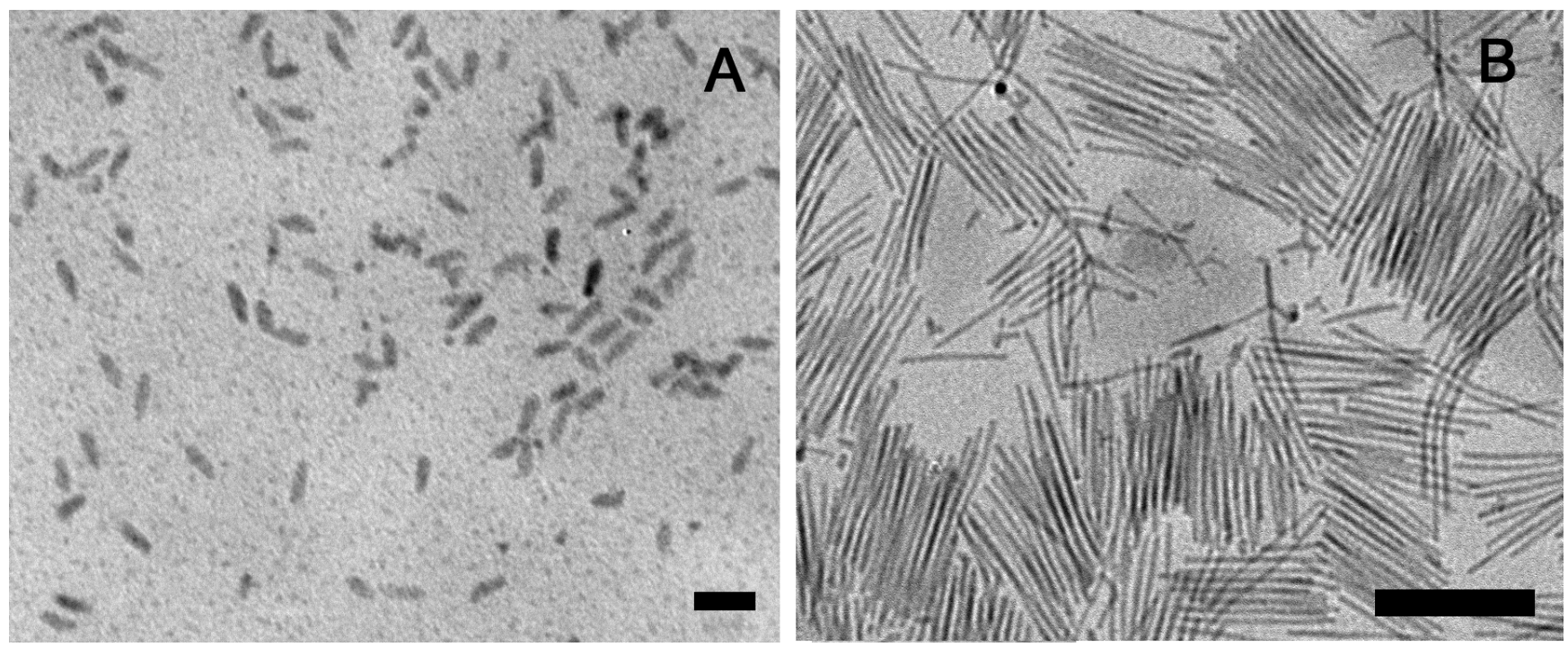
Figure S9 UV-Vis spectrum of CdSe nanocrystals prepared using Cd-ODPA and TOPSe in TOPO at $260{ }^{\circ} \mathrm{C}$ using double degassed protocol.

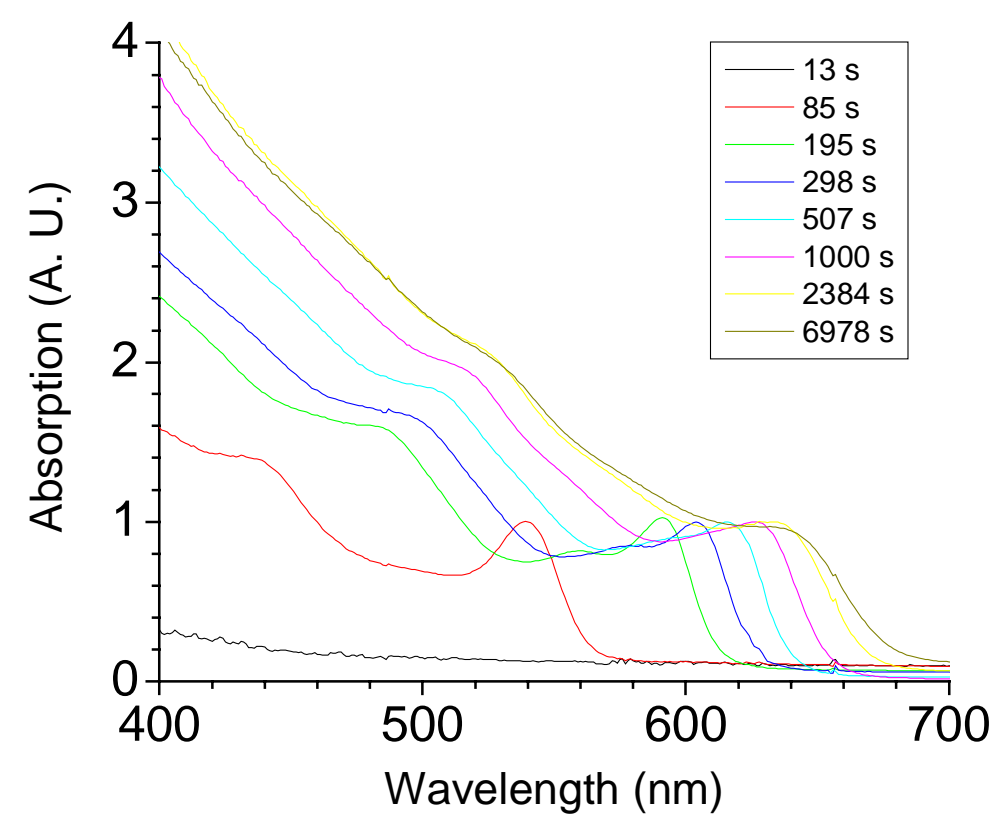


$\mathbf{H}_{2}{ }^{18} \mathbf{O}$-TOP ${ }^{16}$ O isotope exchange. To a $25 \mathrm{~mL}$ three-neck flask was added TOPO (2.73 g, $\left.7.06 \mathrm{mmol}\right)$, $\mathrm{H}_{2}$-ODPA $(1.07 \mathrm{~g}, 3.2 \mathrm{mmol})$, and $\mathrm{CdO}(0.207 \mathrm{~g}, 1.6 \mathrm{mmol})$. The mixture was degassed at $120{ }^{\circ} \mathrm{C}, 300$ mtorr for $20 \mathrm{~min}$. The flask was then filled with $\mathrm{Ar}$ and heated to $320^{\circ} \mathrm{C}$ to dissolve $\mathrm{CdO}$ giving a pale yellow solution. The reaction was cooled to $160{ }^{\circ} \mathrm{C}$ and the pressure was reduced to $\sim 500$ mtorr for 33 min. The mixture was heated to $290{ }^{\circ} \mathrm{C}$ under $\mathrm{Ar}$ and $\mathrm{H}_{2}{ }^{18} \mathrm{O}$ (Isotech, $95 \%$ min ${ }^{18} \mathrm{O}, 56 \mathrm{mg}, 3.1 \mathrm{mmol}$ $\mathrm{H}_{2}{ }^{18} \mathrm{O}$ ) was injected at this temperature via a syringe. Aliquots of the mixture were taken via a syringe and dissolved in methanol. ${ }^{31} \mathrm{P}$ NMR spectrum of the methanol solution showed presence of $\mathrm{TOP}^{18} \mathrm{O}$ (Figure $\mathrm{S} 10){ }^{1} \mathrm{~A} \mathrm{~S}_{\mathrm{N}} 2$ mechanism has been suggested for this isotope exchange reaction. ${ }^{2}$

Figure S10. ${ }^{31} \mathrm{P}$ NMR $\left(\mathrm{CH}_{3} \mathrm{OH} / \mathrm{CDCl}_{3}\right)$ of TOPO after injecting $\mathrm{H}_{2}{ }^{18} \mathrm{O}$ to a mixture of TOPO and $\mathrm{Cd}$ -ODPA at $290{ }^{\circ} \mathrm{C} .{ }^{a}$

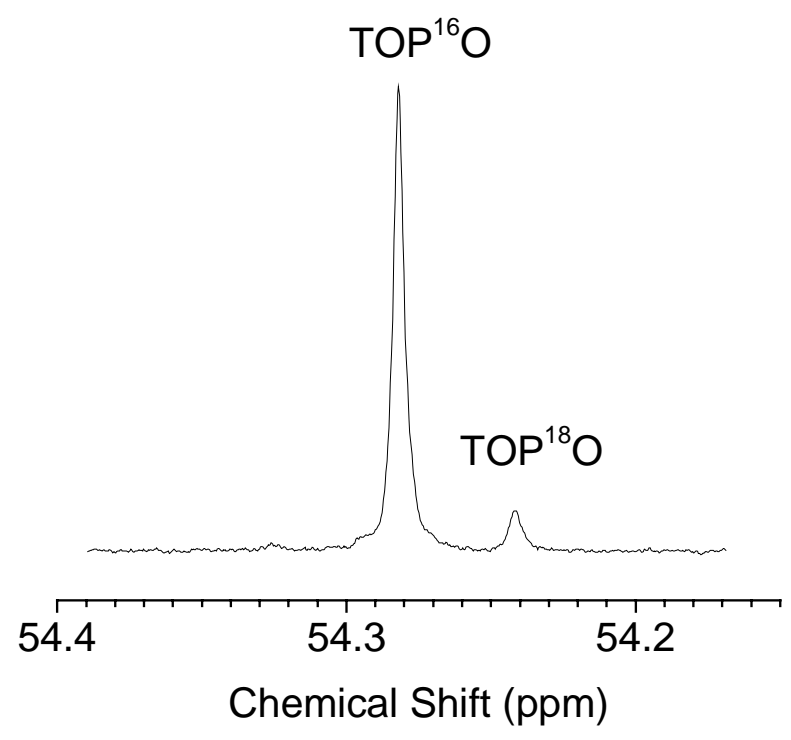

${ }^{a}$ This sample was taken 24 min after the injection of $\mathrm{H}_{2}{ }^{18} \mathrm{O}$. 
Activation parameters of the CdSe synthesis using Cd-OA and TBPSe. A stock solution was prepared by mixing Cd-OA complex (The crude reaction mixture of the Cd-OA synthesis instead of the stock solution was used in this case. $0.8014 \mathrm{~g}, \mathrm{Cd}: 0.65 \mathrm{mmol}, \mathrm{OA}: 2.6 \mathrm{mmol})$, TBPSe $(0.1823 \mathrm{~g}, 0.64$ mmol), ethylphosphonic acid diethyl ester (internal standard, $0.0163 \mathrm{~g}, 0.64 \mathrm{mmol}$ ), and n-decane-d $\mathrm{d}_{22}$ $(0.8129 \mathrm{~g})$. The stock solution was dispersed into four $5 \mathrm{~mm}$ NMR tubes. The samples were degassed by 4 cycles of freeze-pump-thraw before the NMR tubes were flame sealed under vacuum. The reaction kinetics were measured at $357.9 \mathrm{~K}, 379.9 \mathrm{~K}, 389.6 \mathrm{~K}$, and $399.8 \mathrm{~K}$ following the method described in the main text. $\Delta H^{\ddagger}=(62.0 \pm 2.8) \mathrm{kJ} \cdot \mathrm{mol}^{-1}, \Delta S^{\neq}=-(145 \pm 8) \mathrm{J} \cdot \mathrm{mol}^{-1} \cdot \mathrm{K}^{-1}$. To rule out the possible interference of ethylphosphonic acid diethyl ester to the reaction, another set of 3 experiments were carried out at $379.5 \mathrm{~K}, 389.6 \mathrm{~K}$, and $399.8 \mathrm{~K}$ without adding any internal standard and gave $\Delta H^{+}=(55.7 \pm 1.7) \mathrm{kJ} \cdot \mathrm{mol}^{-1}$ and $\Delta \mathrm{S}^{\ddagger}=-(157 \pm 5) \mathrm{J} \cdot \mathrm{mol}^{-1} \cdot \mathrm{K}^{-1}$. 
Reaction kinetics of CdSe synthesis using CdMe 2 in TOPO. TOPO (2.73 g) and $\mathrm{H}_{2}$-ODPA (1.07 g) was degassed at $120^{\circ} \mathrm{C}, 200 \mathrm{mtorr}$ for $47 \mathrm{~min}$. The flask was then filled with $\mathrm{Ar}$ and $\mathrm{CdMe}_{2}(0.225 \mathrm{~g}$, $1.6 \mathrm{mmol}$ ) was added dropwise via a syringe. The mixture was then heated to $267^{\circ} \mathrm{C}$ and TOPSe $(0.638$ $\mathrm{g}, 1.4 \mathrm{mmol}$ ) was injected. The temperature was set to $260{ }^{\circ} \mathrm{C}$ after the injection and aliquots were taken and analyzed according to the procedure described in the main text (Figure S11).

Figure S11. Reaction kinetics of CdSe synthesis using $\mathrm{CdMe}_{2}$ as $\mathrm{Cd}$ precursor at $260{ }^{\circ} \mathrm{C} \cdot k_{\mathrm{obs}}=$ $(3.0 \pm 0.4) 10^{-3} \mathrm{~s}^{-1}$.

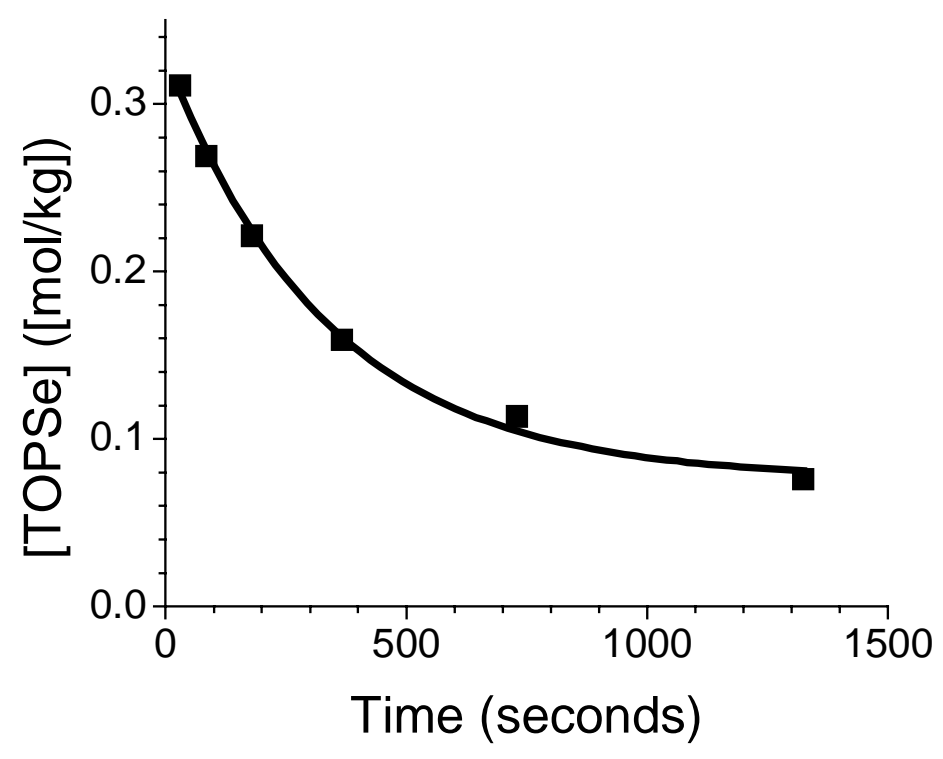


Decomposition of TOPSe in TOPO/H $\mathbf{H}_{2}-\mathrm{ODPA}$ in the absence of $\mathbf{C d}^{2+}$. TOPO $(1.0 \mathrm{~g})$ and $\mathrm{H}_{2}$-ODPA $(0.50 \mathrm{~g})$ were heated to $290{ }^{\circ} \mathrm{C}$ under Ar before TOPSe $(0.537 \mathrm{~g})$ was injected at this temperature. Water $(0.1 \mathrm{~mL})$ was added to the reaction mixture via a syringe $83 \mathrm{~min}$ after the injection of TOPSe. ${ }^{31} \mathrm{P}$ NMR showed that $7 \%$ and $15 \%$ of TOPSe was consumed at 79 min and 265 min after the injection of TOPSe, respectively. 
Figure S12. Reaction kinetics of $\mathrm{CdS}$ synthesis using $\mathrm{CdO}$ as $\mathrm{Cd}$ precursor at $290{ }^{\circ} \mathrm{C} . k_{\mathrm{obs}}=(9.5 \pm$ $1.5) 10^{-4} \mathrm{~s}^{-1}$ (with added water) and (9.0 \pm 5.4$) 10^{-4} \mathrm{~s}^{-1}$ (double degassed)

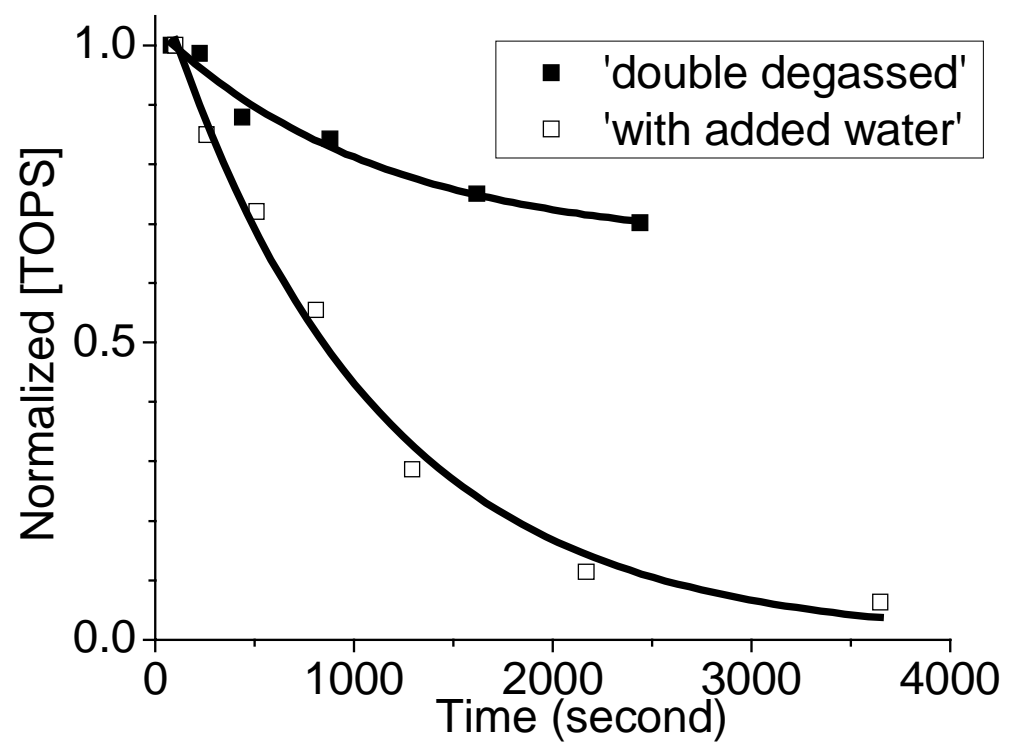




\section{Reference}

1. Risley, J. M.; Vanetten, R. L., Int. J. Chem. Kinet. 1984, 16, 1167.

2. Denney, D. B.; Tsolis, A. K.; Mislow, K., J. Am. Chem. Soc. 1964, 86, 4486. 